\title{
Evaluation of In Vitro Wound Healing Activity of Thymoquinone
}

\author{
Murat Pekmez $^{1}$ (D), Nihan Sultan Milat ${ }^{2}$ (D) \\ 'Istanbul University, Faculty of Science, Department of Molecular Biology and Genetics, Istanbul, Turkey \\ ${ }^{2}$ Istanbul University, Institute of Graduate Studies in Sciences, Department of Molecular Biology and Genetics, Istanbul, Turkey
}

ORCID IDs of the authors: M.P. 0000-0002-6150-8372; N.S.M. 0000-0002-0795-8030

Please cite this article as: Pekmez M, Milat NS. Evaluation of In Vitro Wound Healing Activity of Thymoquinone. Eur J Biol 2020; 79(2): 151-156. DOI: 10.26650/EurJBiol.2020.0044

\section{ABSTRACT}

Objective: Nigella sativa has been extensively investigated as an important potential agent for the healing of wounds and there have been numerous studies regarding its effect. Although thymoquinone (TQ) is a well-known active constituent of Nigella sativa, studies in to the usability of TQ on wound healing are still insufficient. In this study, we aimed to evaluate the in vitro wound healing potential of TQ.

Materials and Methods: NIH/3T3 mouse embryonic fibroblast cells were used to evaluate the wound healing effect of TQ. Different concentrations of TQ $(0.1,1$ and $10 \mu \mathrm{M})$ were applied to the cells and their cytotoxic effect on cells after 24- and 48- hours was measured by MTT assay. Its effect on wound healing after 18- and 24- hours recovery was examined by in vitro scratch assay. Also, the level of $\beta$-catenin, an effective protein in the process of healing wounds, was determined by Western blot assay.

Results: MTT analysis indicated that $0.1,1$ and $10 \mu \mathrm{M}$ doses of TQ had increased the cell numbers. In vitro scratch assay data showed that treatment with 1 and $10 \mu \mathrm{M}$ TQ resulted in a statistically significant wound closure activity $(91.35 \%$ and $90.84 \%$, respectively) compared to the control. Additionally, we observed a statistically significant increase in the $\beta$-catenin protein level which supported our data.

Conclusion: Our results demonstrated that TQ increases both the viability of $\mathrm{NIH} / 3 \mathrm{~T} 3$ cells and its wound closure activity in vitro, and that it has the effect of increasing crucial protein $\beta$-catenin. This study suggests that TQ may be a valuable substance for the healing of wounds and that its usability should be investigated.

Keywords: Thymoquinone, wound healing, NIH/3T3

\section{INTRODUCTION}

Wounds are physical injuries that cause disruption to the normal structure and function of the skin (1). Different types of wounds may occur in humans. The most difficult wounds to heal are chronic wounds and delayed acute wounds. Current studies demonstrate that nearly 6 million people in the world have chronic wounds. Annual health care expenditure is extremely high for these types of wounds, at more than $\$ 3$ billion $(2,3)$. In addition, it is estimated that $1 \%$ of the European population suffers from recurrent and chronic ulceration such as leg and foot ulcers $(2,4)$. Wounds related to diabetics, burns, and ulcers still have significant impact on the population. Therefore, to develop new strategies is important and recent studies have increasingly focused on natural products to treat wounds.

The current synthetic therapeutics used in wound healing still remains insufficient. They may cause adverse reactions and allergic problems that limit the use of these drugs. In order to eliminate these conditions, the development of wound healing agents taken from sources such as medicinal plants and natural products is highly important. For this reason, numerous medicinal plants have been described in the literature such as Curcuma 
longa, Moringa oleifera, Aegle marmelos, Phyllanthus muellerianus and so on (5). One of these plants is Nigella sativa, an herbaceous plant, which belongs to family of the Ranunculaceae (6). It has been used traditionally for the treatment of diseases. It has antimicrobial, antiviral, antifungal, antiparasitic properties (7). In vitro and in vivo studies have proved that it might be useful for wound healing. In studies performed on in vivo burn models, it was demonstrated that $N$. sativa cream and $N$. sativa extract showed significant wound healing effects compared with a commercially available cream $(6,8)$. In the in vivo diabetic model, it was shown that the wound area decreased as a result of the treatment of $N$. sativa extract (9). It is also reported that $N$. sativa extract reduces radiation-related delayed wound healing in mice (10). When human gingival fibroblast cells are used as an in vitro wound healing model, aqueous extract of $N$. sativa induced fibroblast proliferation and accelerated wound closure activity (1). All these healing effects and properties originate from bioactive compounds of $N$. sativa such as thymoquinone (TQ). It is known that Thymoquinone has antimicrobial $(11,12)$, antiallergic (13), antidiabetic (14), anti-inflammatory (15), and antioxidant (16) properties . These properties make TQ an important potential agent for the healing of wounds. Interestingly, the wound healing potential of TQ has not been clearly investigated. Moreover, most of the studies are based on the in vivo models. However, in vitro studies are needed to highlight the wound healing mechanism at molecular level.

Thus far, there have been numerous studies on the wound healing effect of $N$. sativa, but studies on TQ are still insufficient. The purpose of this study is to evaluate the role of TQ on the wound healing process and on $\beta$ - catenin expression in $\mathrm{NIH} / 3 \mathrm{~T} 3$ fibroblast cell line.

\section{MATERIALS AND METHODS}

\section{Experimental Reagents}

TQ was purchased from Santa Cruz Biotechnology (Dallas, Texas, USA) and dissolved in dimethyl sulfoxide (DMSO). Tissue culture reagents were obtained from Gibco (Carlsbad, CA, USA). SMART ${ }^{\text {TM }}$ BCA Protein Assay Kit was from iNtRON Biotechnology (Seongnam, Gyeonggi, Korea). Polyvinylidene fluoride (PVDF) membrane was obtained from Millipore (Darmstadt, Germany). Mouse anti- $\beta$-catenin monoclonal antibody and horseradish peroxidase (HRP)-conjugated goat anti-mouse IgG were obtained from Enzo Life Sciences (Farmingdale, NY, USA). HRP conjugated GAPDH Loading Control Monoclonal Antibody and Pierce $^{\mathrm{TM}}$ ECL Western Blotting Substrate was from ThermoFisher Scientific (Kwartsweg, Bleiswijk, Holland). All other chemicals and reagents were from Sigma (St. Louis, MO, USA).

\section{Cell Culture}

Mouse embryonic fibroblast cells (NIH/3T3) were kindly provided by Istanbul University Faculty of Science, Department of Biology. NIH/3T3 cells were cultured in Dulbecco's modified Eagle medium (DMEM/F12) which included 1\% ( $/ / v)$ antimycotic-antibiotic solution $(100 \mu \mathrm{g} / \mathrm{mL}$ streptomycin and $0.25 \mu \mathrm{g} / \mathrm{mL}$ amfoterisin $\mathrm{B}$ and $100 \mathrm{U} / \mathrm{mL}$ penicillin) and 10\% (v/v) heat-inac- tivated fetal bovine serum. The cells were incubated at $37^{\circ} \mathrm{C}$ in a humidified atmosphere with $5 \% \mathrm{CO}_{2}$. The cells were passaged before they reached full confluence.

\section{Cell Viability Assay}

MTT (3-(4,5-dimethylthiazol-2-yl)2,5-diphenyl tetrazolium bromide) cell viability assay was used in order to investigate the proliferative and cytotoxic effect of TQ on NIH/3T3 fibroblast cells. Briefly, the cells were seeded in a 96-well plate at a confluency of $3 \times 10^{4}$ per well. Adherent cells were then treated with increasing concentrations of TQ (0.01-1000 $\mu \mathrm{M})$ which was diluted with DMEM/F12. After 24 and $48 \mathrm{~h}$ incubation at $37^{\circ} \mathrm{C}$, the medium was removed. $30 \mu \mathrm{L}$ of MTT $(5 \mathrm{mg} / \mathrm{ml})$ was added to the cells. After a $4 \mathrm{~h}$ incubation at $37^{\circ} \mathrm{C}, 150 \mu \mathrm{L}$ of DMSO was added to solubilize formazan crystals and the absorbance was measured at $540 \mathrm{~nm}$ using a microplate reader. Experiments were performed in triplicate.

\section{Thymoquinone Treatment}

$\mathrm{NIH} / 3 \mathrm{~T} 3$ cells were seeded in 24 well-plates at a density of $1.8 \times 10^{5}$ per well for cell treatment with TQ. According to MTT assay results, final TQ concentrations of $0.1,1$ and $10 \mu \mathrm{M}$ were applied to the cells incubated for $24 \mathrm{~h}$. Experiments were performed in triplicate.

\section{In vitro Scratch Assay}

The capability of TQ on migration of NIH/3T3 cells was determined by in vitro scratch assay. The cells were seeded at a confluency of $18 \times 10^{4}$ per well into a 24 -well plate containing DMEM/ F12 medium and incubated overnight. After incubation, the medium was removed and the adherent cells were scratched with a sterile $\mathrm{p} 1000$ pipette tip. The scratched cell layers were washed with phosphate buffered saline (PBS) to remove cell debris. After that, the cells were treated with $0.1,1,10 \mu \mathrm{M}$ of TQ that was diluted in DMEM/F12. Fresh medium was applied for the control group. Photographs of the scratched area were recorded by inverted light microscope equipped with a camera (Nikon Eclipse Ti-E) under 10X magnification at 0, 18 and $24 \mathrm{~h}$. Data were analyzed with Image J software (NIH, USA) in order to determine the width of the scratch and the rate of migration of cells. Experiments were performed in triplicate.

\section{Immunoblotting Assay}

Western blotting assay was performed to analyze samples, as described by Şengelen and Önay-Uçar (17). In short, the cells were trypsinized and centrifugated at $700 \times \mathrm{g}$ for $10 \mathrm{~min}$. Lysis buffer [20 mM Tris-HCl (pH 6.8), 0.04\% (w/v) EDTA, 1\% (v/v) Triton X-100, and EDTA-free PIC (protease inhibitor cocktail), $1 \mathrm{mM}$ PMSF] was used to resuspend the pellets. The extracts were centrifuged at $20,000 \times \mathrm{g}$ for $20 \mathrm{~min}$ at $4^{\circ} \mathrm{C}$. Protein concentrations were quantified by bicinchoninic acid protein assay. Thirty $\mu \mathrm{g}$ of protein was separated by SDS-PAGE gel and transferred onto PVDF membranes. 5\% non-fat dry milk in Tris-buffered saline/ Tween 20 (TBST) was used to block membranes for $1 \mathrm{~h}$. After that, the membranes were incubated overnight with anti- $\beta$-catenin primer antibody $(1: 1000)$ at $4^{\circ} \mathrm{C}$. The following day, the membranes were washed five times with TBST, and then incu- 
bated with IgG-HRP secondary antibody $(1: 5000)$ for $2 \mathrm{~h}$ at $37^{\circ} \mathrm{C}$, and washed with TBST again. Protein bands were visualized using an ECL kit. GAPDH (antibody diluted 1:2000) was used for data normalization. ImageLab 5.2.1 software (Bio-Rad) was used to determine protein expression levels. Experiments were performed in triplicate.

\section{Statistical Analysis}

One-way or two-way ANOVA was used to analysis data followed by Tukey post-hoc-test. The statistically significance was taken to be $P<0.05$. The results were presented as mean \pm standard deviation (SD) and the number of experiments were indicated with $n$. Statistical analysis and graph generation were carried out in GraphPad Prism Software (San Diego, CA, USA) version 7.0.

\section{RESULTS}

\section{Thymoquinone Effects Viability of NIH/3T3 Cells}

The effect of increasing concentrations of TQ on cell viability was evaluated in NIH/3T3 after $24 \mathrm{~h}$ and $48 \mathrm{~h}$ incubation using MTT assay. The data is shown in Figure 1. The cells were treated with $0.01-1000 \mu \mathrm{M}$ of TQ. MTT results showed that 1 and $10 \mu \mathrm{M}$ of TQ was able to promote cell viability. However, $50 \mu \mathrm{M}$ and above of TQ showed decreased cell viability after $24 \mathrm{~h}$ incubation. In addition, the data showed that TQ decreased cell viability of NIH/3T3 cells in a dose-dependent manner after $48 \mathrm{~h}$ incubation. The half-maximal inhibitory concentration $\left(\mathrm{IC}_{50}\right)$ was determined $51.43 \mu \mathrm{M}$ after $24 \mathrm{~h}$ and $47.71 \mu \mathrm{M}$ after $48 \mathrm{~h}$ incubation. According to the MTT results, different concentration of TQ was used and selected according to significantly increased cell viability compared to thecontrol. Therefore, the final concentrations of thymoquinone which are $0.1,1$ and $10 \mu \mathrm{M}$ were used in the experiments.

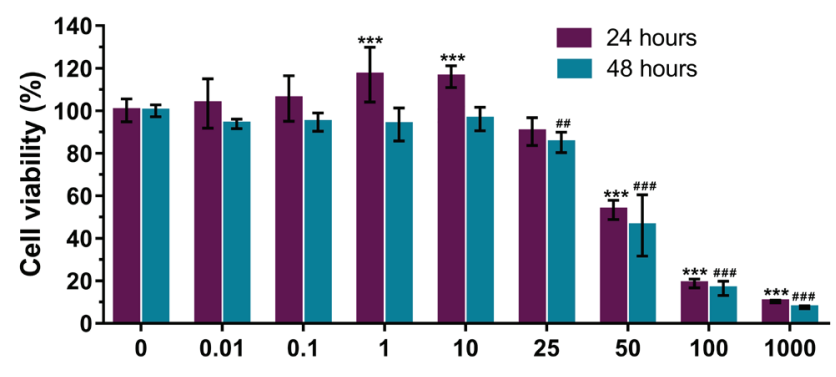

Thymoquinone concentration $(\mu \mathrm{M})$

Figure 1. Determination of TQ effect on cell viability after 24 $\mathrm{h}$ and $48 \mathrm{~h}$ incubation. The graph represents the mean $\pm \mathrm{SD}$ of three independent experiments analyzed together $(n=3)$. ${ }^{* * *} P<0.001$ compared to control for $24 \mathrm{~h},{ }^{\# \#} P<0.001$, ${ }^{\#} P<0.01$ compared to control for $48 \mathrm{~h}$ determined by one-way ANOVA using Tukey post-hoc-test.

\section{The Effect of Thymoquinone on NIH/3T3 Cells Wound Healing} In vitro scratch assay was used to determine wound closure activity of TQ on NIH/3T3 cells after 18 and 24 h recovery. In vitro scratch assay data showed that, although there was no statisti- cally significant difference between $0.1 \mu \mathrm{M}$ TQ and the control groups, treatment with 1 and $10 \mu \mathrm{MTQ}$ resulted in a statistically significant recovery in the wound area compared to the control after 18 and $24 \mathrm{~h}$ (Figures 2 and 3). The closure of the control was $57.9 \%, 64.98 \%$ for $0.1 \mu \mathrm{M}, 75.38 \%$ for $1 \mu \mathrm{M}$ and $71.82 \%$ for $10 \mu \mathrm{M}$ after $18 \mathrm{~h}$ of incubation. After $24 \mathrm{~h}$ of incubation, the clo-

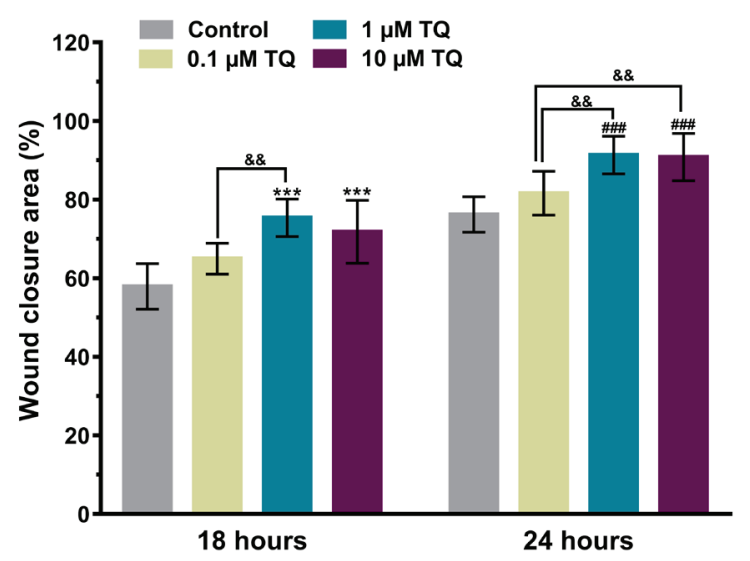

Figure 2. Percentage of wound closure area of NIH/3T3 fibroblast cells treated with TQ determined by in vitro scratch assay after 18 hours and $24 \mathrm{~h}$ incubation. The graph represents the mean \pm SD of three independent experiments analyzed together $(\mathrm{n}=3)$ ). ${ }^{* *} P<0.001$ compared to control for $18 \mathrm{~h},{ }^{\# \#} P<0.001$ for $24 \mathrm{~h} .{ }^{\&} \&<<0.01$ shows multiple comparisons between different groups. $P$ values were determined by one-way ANOVA using Tukey post hoc-test.
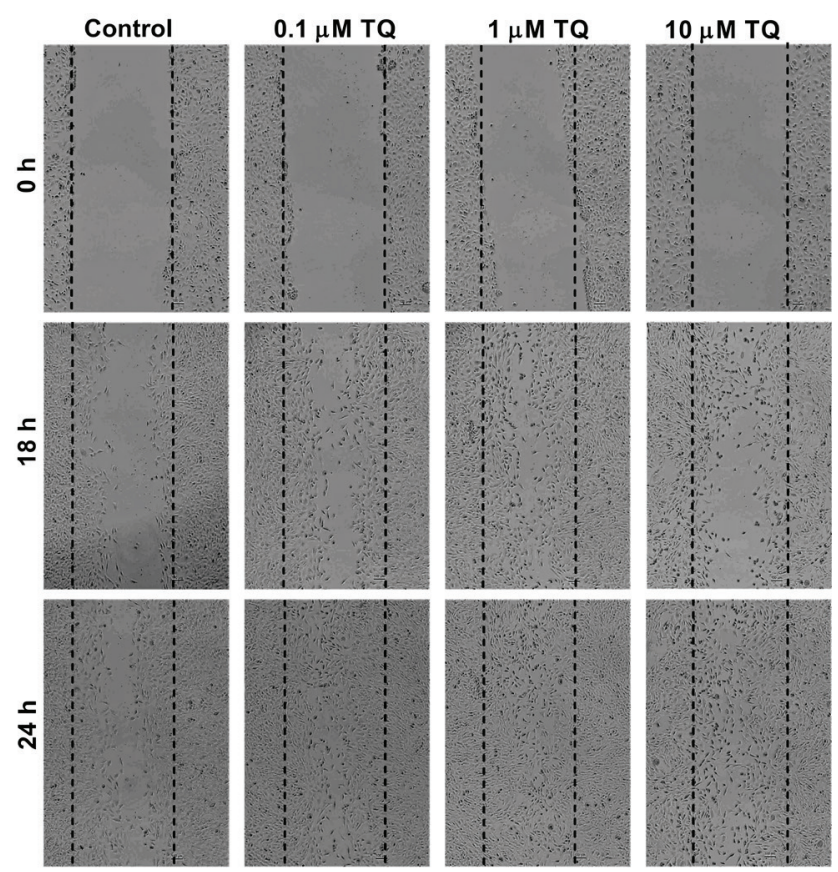

Figure 3. Microscopy images of NIH/3T3 fibroblast cells migration after scratch at 0,18 and $24^{\text {th }} \mathrm{h}$ of $0.1,1$ and $10 \mu \mathrm{M} \mathrm{TQ}$ treatment under $10 \mathrm{X}$ magnification. 
sure of the control was $76 \%, 81.64 \%$ for $0.1 \mu \mathrm{M}, 91.35 \%$ for $1 \mu \mathrm{M}$ and $90.84 \%$ for $10 \mu \mathrm{M}$. According to the results, $1 \mu \mathrm{M}$ of TQ was observed as the most efficient concentration for in vitro wound healing activity on $\mathrm{NIH} / 3 \mathrm{~T} 3$ cells.

\section{Determination of $\beta$-catenin Expression in NIH/3T3 Fibro- blast Cells}

Western blotting assay was performed to analyze the effect of TQ on $\beta$-catenin expression in $\mathrm{NIH} / 3 \mathrm{~T} 3$ fibroblast cells (Figure 4). We observed that $1 \mu \mathrm{M}$ TQ treatment increased $\beta$-catenin expression. No statistically significant difference was observed between 0.1 and $10 \mu \mathrm{M}$ TQ groups compared to the control $(P>0.05) .1 \mu \mathrm{M}$ TQ increased the expression of $\beta$-catenin by $35.2 \%$. In contrast, $0.1 \mu \mathrm{M}$ and $10 \mu \mathrm{M}$ TQ decreased the level of $\beta$-catenin by $12.5 \%$ and $4.6 \%$ respectively.
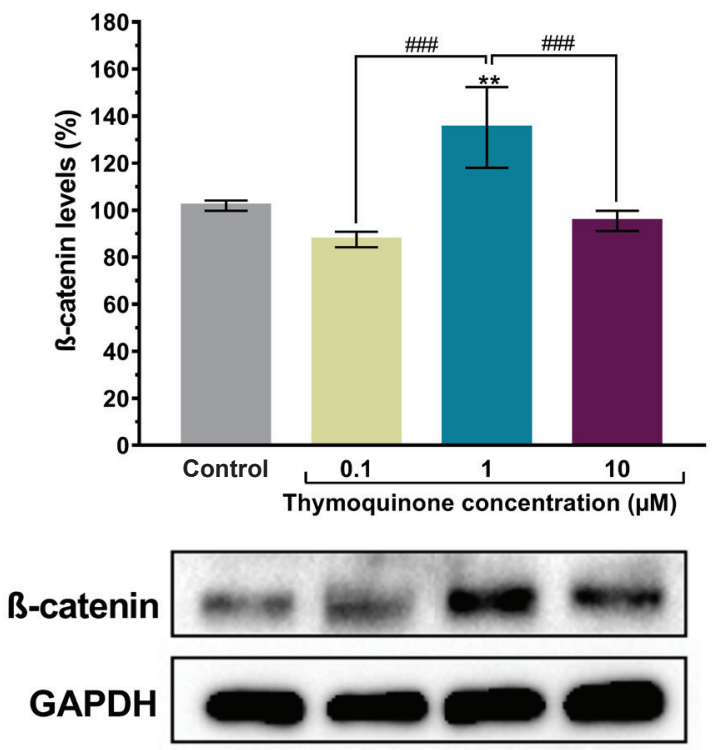

Figure 4. Expression of $\beta$-catenin in response to TQ $(0.1,1$ and $10 \mu \mathrm{M})$ treatments for $24 \mathrm{~h}$. All data were normalized to GAPDH. The graph represents the mean $\pm S D(n=3)$. ${ }^{* *} P<0.01$ versus control group. ${ }^{\# \#} P<0.001$ shows multiple comparisons between different groups. $P$ values were determined by one-way ANOVA using Tukey post hoc-test.

\section{DISCUSSION}

Wounds are still a major global health challenge. Many people suffer from different types of wounds. Although synthetic therapeutics form the basis of wound care, they may cause side effects and allergic problems so the use of these drugs are limited. Current studies have also reported the positive effects of natural products and their bioactive constituents. Many medicinal plants are screened as a wound healing agent and one of these medicinal plants is $N$. sativa. Studies carried out to date have shown the significant wound healing effects of $N$. sativa extracts and oils in vivo burn models $(6,8)$, diabetic wound models (9), radiation-related delayed wound models (10) and in vitro wound models (1). Although these studies suggest that
$N$. sativa oil or extract is a wound healing agent, none of them explained which active constituent provides a healing effect on wounds. As is well known, many bioactive compounds are found as a mixture in extracts or oils of medicinal plants. They may cause various side effects such as allergies or irritation. This limits the use of commercially available impure extracts and oils of $N$. sativa as a wound healing agent. In addition, it has been reported that $N$. sativa extract and oil cause irritation or allergic problems $(18,19)$. Therefore, research should focus on active components of $N$. sativa.

Many studies have reported on and evaluated the wound healing effect of natural bioactive components. In diabetic wound healing models, treatment with curcumin provided acceleration of wound healing by its antioxidant effect (20). A study performed on uterine wounds treated with resveratrol showed an increasing activity of antioxidant enzymes and decreasing lipid peroxidation. That resulted in thickness of the uterine wall (21). Furthermore, rosmarinic acid demonstrated anti-inflammatory properties in thermal injury and liver ischaemia-reperfusion rat models (22). TQ is the main biologically active component of essential oil of N. sativa, also well known for its pharmacological activities such as antimicrobial $(11,12)$, anti-inflammatory (15), antioxidant (16) effects. According to these known properties, TQ has been thought to have potential as a wound healing agent.

Herein, our results indicated that low concentrations of TQ significantly increased $\mathrm{NIH} / 3 \mathrm{~T} 3$ cell viability in both a dose and time dependent manner. The highest cell viability was observed after $24 \mathrm{~h}$ incubation with 1 and $10 \mu \mathrm{M}$ TQ, but at high concentrations (>25 $\mu \mathrm{M})$, cell viability significantly decreased. Additionally, all concentrations of TQ decreased cell viability after $48 \mathrm{~h}$. According to these results, the study was carried out with $24 \mathrm{~h}$ of treatment. IC $\mathrm{C}_{50}$ value of TQ was determined as $51.43 \mu \mathrm{M}$. These results suggest that higher doses $(>25 \mu \mathrm{M})$ of $\mathrm{TQ}$ and longtime treatment are more toxic to $\mathrm{NIH} / 3 \mathrm{~T} 3$ fibroblast cells. Thus, low doses of TQ are more effective for cell viability in healthy fibroblast cells. One study showed that TQ accelerated the rate of wound closure by reducing inflammation and oxidative stress in burn models (23). Another study performed with alloxan-induced diabetic rats resulted in acceleration of wound healing after TQ treatment during the inflammatory phase which arose due to the antioxidant, anti-inflammatory and antimicrobial properties of TQ (24). Our study is consistent with these studies as well as valuable because more thorough investigation is needed in vitro with different cell types which act during the phases of wound healing to determine the process at cellular and molecular level and understand the role of TQ. Additionally, the results of treatments with potential agents will be predictable when in vivo studies are performed.

In vitro models, wound healing is indicated with migration of cells and explains the rate of wound closure. The in vitro scratch assay is an easy method to measure cell migration in vitro (25). Accordingly, we used in vitro scratch assay to create a wound area and to test TQ treatments in vitro. The photographs taken at 0,18 and $24 \mathrm{~h}$ time intervals to observe the closure of the wound 
area clearly indicated that all selected doses of TQ $(0.1,1$ and 10 $\mu \mathrm{M})$ have potential wound closure activity due to fibroblast migration. In addition, while 1 and $10 \mu \mathrm{M}$ TQ showed a statistically significant effect in comparison with the control $(P<0.001)$, the highest wound closure rate was observed in $1 \mu \mathrm{M} \mathrm{TQ}$ treatment. The rate of wound closure is increasingly thought to be related to the idea that TQ may also promote the proliferation of cells.

Following an injury, the wound healing response is controlled by many signaling pathways (26). Studies should be carried out to understand these molecular pathways and their components which are involved in the wound healing process in order to generate potential therapeutic agents and therapies. The canonical Wnt-wingless signaling pathway is well known which regulates many biologic processes by increasing the transcriptional activity and stability of $\beta$-catenin (27-29). Additionally, Wnt pathway is important for wound healing because its key mediator $\beta$-catenin has a pivotal role on the proliferation phase of wound healing. $\beta$-catenin also participates in some phases of wound repair. First the phosphorylation occurs and it accumulates in the cytoplasm and then migrates into the nucleus. In the nucleus the regulation of the target gene transcription occurs and this results in proliferation, migration and accumulation in the collagen of fibroblasts. Our western blot analysis data is showed that $1 \mu \mathrm{M}$ TQ treatment resulted in an increase by $35.2 \%$ in $\beta$-catenin expression compared with other selected doses of TQ $(P<0.001)$. It might be thought that TQ plays a role in the activity of $\beta$-catenin. To better understand the results of elevated $\beta$-catenin protein levels after TQ treatment on wound healing, more parameters should be investigated, and further studies should be performed in vivo physiological conditions.

\section{CONCLUSION}

Our results show that TQ may promote cell viability, accelerate wound healing and trigger protein levels which are effective in wound healing phases in vitro. Our results reveal promising data regarding the possibility of a TQ derived product being used in the treatment of wounds and other dermatological problems. TQ derived products and drugs may be developed combined with other active substances and/or administered topically. Although the study was performed in one of the important cell groups, fibroblasts, on wound healing, further research should be carried out with other cell lines to determine TQ usability on wound healing and understand its effect on the wound healing mechanism.

Peer-review: Externally peer-reviewed.

Author Contributions: Conception/Design of study: M.P., N.S.M..; Data Acquisition: M.P., N.S.M.; Data Analysis/Interpretation: M.P., N.S.M.; Drafting Manuscript: M.P., N.S.M.; Critical Revision of Manuscript: M.P., N.S.M; Final Approval and Accountability: M.P., N.S.M..; Technical or Material Support: M.P., N.S.M.; Supervision: M.P.

Conflict of Interest: The authors declare that they have no conflicts of interest to disclose.
Financial Disclosure: There are no funders to report for this submission.

\section{REFERENCES}

1. Ab Rahman MR, Abdul Razak F, Mohd Bakri M. Evaluation of wound closure activity of Nigella sativa, Melastoma malabathricum, Pluchea indica, and Piper sarmentosum extracts on scratched monolayers of human gingival fibroblasts. J Evid Based Complementary Altern Med 2014; 1-9.

2. Mathieu D, editor. Handbook on hyperbaric medicine. New York: Springer; 2006.

3. Menke NB, Ward KR, Witten TM, Bonchev DG, Diegelmann RF. Impaired wound healing. Clin Dermatol 2007; 25: 19-25.

4. Nelzen O, Bergqvist D, Lindhagen A. The prevalence of chronic lower-limb ulceration has been underestimated: Results of a validated population questionnaire. Br J Surg 1996; 83: 255-8.

5. Agyare C, Bekoe EO, Boakye YD, Dapaah SO, Appiah T, Bekoe SO. Medicinal Plants and Natural Products with Demonstrated Wound Healing Properties. Wound Healing: New insights into Ancient Challenges. London: InTech; 2016.

6. Sarkhail P, Esmaily H, Baghaei A, Shafiee A, Abdollahi M, Khademi $Y$, et al. Burn healing potential of Nigella sativa seed oil in rats. Int J Pharm Sci Res 2011; 2(1): 34-40.

7. Eid AM, Elmarzugi NA, Abu Ayyash LM, Sawafta MN, Daana HI. A Review on the Cosmeceutical and External Applications of Nigella sativa. J Trop Med 2017; 1-6.

8. Yaman I, Durmus AS, Ceribasi S, Yaman M. Effects of Nigella sati$v a$ and silver sulfadiazine on burn wound healing in rats. Vet Med (Praha) 2010; 55(12): 619-24.

9. Nourbar E, Mirazi N, Yari S, Rafieian-Kopaei M, Nasri H. Effect of hydroethanolic extract of Nigella sativa L. on skin wound healing process in diabetic male rats. Int J Prev Med 2019; 10:18-24.

10. Jagetia GC, Ravikiran P. Acceleration of wound repair and regeneration by Nigella sativa in the deep dermal excision wound of mice whole body exposed to different doses of $\gamma$-radiation. Am Res J Med Surg 2015; 1(3): 1-17.

11. Kouidhi B, Zmantar T, Jrah H, Souiden Y, Chaieb K, Mahdouani K et al. Antibacterial and resistance-modifying activities of thymoquinone against oral pathogens. Ann Clin Microbiol Antimicrob 2011; 10: 29-35.

12. Halawani E. Antibacterial Activity of Thymoquinone and Thymohydroquinone of Nigella sativa L. and Their Interaction with Some Antibiotics. Adv Biol Res 3. 2009; (5-6): 148-52.

13. Hayat K, Asim MB, Nawaz M, Li M, Zhang L, Sun N. Ameliorative effect of thymoquinone on ovalbumin-induced allergic conjunctivitis in Balb/c mice. Curr Eye Res 2011; 36(7): 591-8.

14. Abdelmeguid NE, Fakhoury R, Kamal SM, Al Wafai RJ. Effects of Nigella sativa and thymoquinone on biochemical and subcellular changes in pancreatic beta-cells of streptozotocin-induced diabetic rats. J Diabetes 2010; 2(4): 256-66.

15. Ali BH, Blunden G. Pharmacological and toxicological properties of Nigella sativa. Phytother Res 2003; 17(4): 299-305.

16. Hosseinzadeh H, Parvardeh S, Asl MN, Sadeghnia HR, Ziaee T. Effect of thymoquinone and Nigella sativa seeds oil on lipid peroxidation level during global cerebral ischemia-reperfusion injury in rat hippocampus. Phytomedicine 2007; 14(9): 621-7.

17. Şengelen A, Önay-Uçar E. Rosmarinic acid and siRNA combined therapy represses Hsp27 (HSPB1) expression and induces apoptosis in human glioma cells. Cell Stress Chaperones 2018; 23(5): 885-96.

18. Zedlitz S, Kaufmann R, Boehncke WH. Allergic contact dermatitis from black cumin (Nigella sativa) oil-containing ointment. Contact Dermatitis 2002; 46(3): 188. 
19. Gelot P, Bara-Passot C, Gimenez-Arnau E, Beneton N, Maillard H, Celerier P. Éruption Bulleuse À L'Huile De Nigelle. Ann Dermatol Venereol 2012; 139(4): 287-91.

20. Kant V, Gopal A, Pathak NN, Kumar P, Tandan SK, Kumar D. Antioxidant and anti-inflammatory potential of curcumin accelerated the cutaneous wound healing in streptozotocin-induced diabetic rats. Int Immunopharmacol 2014; 20: 322-30.

21. Sayin O, Micili SC, Goker A, Kamaci G, Ergur BU, Yilmaz O et al. The role of resveratrol on full-Thickness uterine wound healing in rats. Taiwan J Obstet Gynecol 2017; 56(5): 657-63.

22. Rocha, J, Eduardo-Figueira M, Barateiro A, Fernandes A, Brites D, Bronze $R$ et al. Anti-inflammatory effect of rosmarinic acid and an extract of Rosmarinus officinalis in rat models of local and systemic inflammation. Basic Clin Pharmacol Toxicol 2015; 116(5): 398-413.

23. Selçuk CT, Durgun $M$, Tekin R, Yolbas $L$, Bozkurt $M, A$ kçay $C$ et al. Evaluation of the effect of thymoquinone treatment on wound healing in a rat burn model. J Burn Care Res. 2013; 34(5): 274-81.
24. Yusmin A, Ahmad N. Effect of thymoquinone on wound healing on wound healing in alloxan-induced diabetic rats. Asian J Pharm Clin Res 2017; 10(9): 242-5.

25. Liang CC, Park AY, Guan JL. In vitro scratch assay: a convenient and inexpensive method for analysis of cell migration in vitro. Nat Protoc 2007; 2(2): 329-33.

26. Bielefeld Kirsten A, Amini-Nik S, Alman BA. Cutaneous wound healing: recruiting developmental pathways for regeneration. Cell Mol Life Sci 2013; 70(12): 2059-81.

27. Polakis P. Wnt signaling and cancer. Genes Dev 2000; 14: 1837-51.

28. Taipale J, Beachy PA. The hedgehog and Wnt signalling pathways in cancer. Nature 2001; 411: 349-54.

29. Korswagen HC, Clevers HC. Activation and repression of wing-less/ Wnt target genes by the TCF/LEF-1 family of transcription factors. Cold Spring Harb Symp Quant Biol 1999; 64: 141-7. 